\title{
Comparative Analysis of Cost of Biomedical Waste Management in Rural India
}

\author{
${ }^{1}$ Bryal D'souza, ${ }^{2}$ Arun MS, ${ }^{3}$ Bijoy Johnson
}

\begin{abstract}
Introduction: The quantum of waste generated from medical care and activities is a global matter of concern. Improper management of biomedical waste (BMW) has a grave health impact on the community, health care professionals, and the environment. ${ }^{1}$ It is mandatory by law that every medical organization that generates waste should have a system, process, and resources in place for segregating BMW within the organization for proper disposal. The present article deals with the understanding of various costs associated in BMW management process that will help the health care organization to prioritize their spending and focus on areas that require spending to achieve compliance in process of BMW management.
\end{abstract}

Materials and methods: Descriptive cross-sectional study was carried out, to study the compliance of BMW management at three different hospitals with respect to Bio-Medical Waste (Management and Handling) Rules, 2011. A retrospective study was conducted to analyze cost data for a 1-year time period. Cost involved in BMW management was analyzed and classified as capital and recurring costs. The study was undertaken in Udupi taluk, and the taluk comprises 11 hospitals (1 Government and 10 private hospitals). The hospitals were selected using convenient sampling as taking permission to conduct the study was difficult. Only three hospitals were permitted to carry out the study.

Results and discussion: Compliance was found to be better in accredited hospital than in nonaccredited hospital. This could be attributed to strict adherence to standard operating procedures and regular training of staff. Cost involved in BMW management was analyzed as capital and recurring costs. Since most of the hospital outsource final disposal, capital costs are significantly less compared to recurring costs. Among the recurring costs, maximum expenditure is on consumables like color-coded bags. Cost per bed per day for handling BMW was calculated and it was found to be higher in smaller hospitals.

Keywords: Biomedical waste, Cost analysis, Health care waste, Medical waste.

How to cite this article: Bryal D'souza, Arun MS, Johnson B. Comparative Analysis of Cost of Biomedical Waste Management in Rural India. Int J Res Foundation Hosp Healthc Adm 2016;4(1):11-15.

\section{${ }^{1,2}$ Assistant Professor, ${ }^{3}$ Junior Resident \\ ${ }^{1}$ Department of Public Health, KMC Manipal University, Manipal Karnataka, India \\ ${ }^{2,3}$ Department of Hospital Administration, KMC Manipal University, Manipal, Karnataka, India}

Corresponding Author: Bryal D'souza, Assistant Professor Department of Public Health, KMC Manipal University, Manipal Karnataka, India, Phone: +919900405393, e-mail: brayal. dsouza@manipal.edu

\section{Source of support: Nil}

Conflict of interest: None

\section{INTRODUCTION}

Biomedical waste (BMW) means any waste which is generated during the diagnosis, treatment, or immunization of human beings or animals or in research activities pertaining thereto or in the production or testing of biologicals, including categories mentioned in Schedule I. ${ }^{1,2}$

In India, it is estimated that there are more than 15,000 small medical institutions and laboratories which also generate significant amounts of BMW. It is estimated that our country generates around three million tons of medical waste every year and the amount is expected to grow at $8 \%$ annually. ${ }^{3}$

Biomedical waste may contain infectious, toxic chemicals causing risk of contamination to both people and the environment. Hospitals should be responsible for the waste they generate. They must ensure that the handling, treatment, and disposal of that waste will not have harmful consequences for community.

To effectively manage BMW at health care institutions, it is important to understand the various cost factors involved in the efficient management. According to $\mathrm{WHO}$, the total cost of a waste management system includes initial capital investment, amortization over the effective life of plant or equipment, operating costs, such as labor and consumables, utility requirement, such as fuel electricity, water, and contractual and overhead costs. ${ }^{4}$

Hospitals can highly reduce the total costs for treatment and disposal of medical wastes by improving their classification method for medical wastes and then employing effective treatment or disposal methods based on the characteristics of their particular medical wastes. ${ }^{5}$

Failure for effectively handling BMW is because of lack of awareness about health hazard related to health care waste, inadequate training in waste management, absence of waste management, absence of disposal system, insufficient financial and human resource, and the low priority given to the topic. ${ }^{6}$ Since the last 3 decades, unregulated BMW handling, treatment, and disposal have become a serious threat to the environment and community. Predictors include lack of awareness, knowledge, attitude of generators of health care waste, availability of resources, and improper disposal mechanism. ${ }^{7}$ 
The Ministry of Environment and Forests notified the "Bio-Medical Waste (Management and Handling) Rules, 1998" in July, 1998. In accordance with the rules (Rule 4), it is the duty of every "Occupier," i.e., a person who has the control over the institution and/or its premises, to take all steps to ensure that the waste generated is handled without any adverse effect to human health and environment. ${ }^{2}$ Some of the factors like awareness about the health hazard of BMW, proper technique, and methods of handling the waste can go a long way toward the safe disposal of hazardous hospital waste and safeguard the community from various adverse effects of the hazardous waste. ${ }^{8}$

\section{Management of BMW within the Institution}

It is statutory on part of every health care facility, from the smallest dispensary to the largest superspecialty hospital to manage BMW. Management of BMW starts from the time of segregation of waste at source, transport by hospital personnel to common disposal area within premises, and final collection by outsourced agency having common BMW treatment facility.

In general, BMW contains noninfectious waste and infectious waste. As regards to the category-wise percentage of waste generation, noninfectious waste is $80 \%$, pathological and infectious waste $15 \%$, sharps $1 \%$, chemical or pharmaceutical waste $3 \%$, and others $1 \% .9$

The waste produced in the course of health care activities carries a higher potential for infection, injury, and pollution due to unscientific disposal and open burning, than any other type of waste. Whenever it is generated, safe and reliable methods for its handling are therefore essential. Inadequate and inappropriate handling of BMW may have serious public health consequences and a significant impact on the environment. ${ }^{9}$

Segregation of waste into different color-coded containers as stipulated under Schedule II of BMW (Management and Handling) Rules, 1998 (Amendment 2011) is one of the most important step in management of BMW. Adequate number of waste bins and color-coded bags have to be provided so that wastes are collected properly.

Wastes are generally collected from various areas of the hospital and transported within the hospital premises by closed designated trolleys. These trolleys are marked with Biohazard symbol.

Most of the hospitals have outsourced final disposal of BMW to common BMW treatment facility. These are licensed facilities which collect BMW from different hospital, transport waste in designated vehicles, and dispose BMW according to rules stipulated under BMW (Management and Handling) Rules, 1998 (Amendment 2011).

\section{Cost of Biomedical Waste Management}

A significant portion of budget has to be earmarked for handling BMW management as per the laid rules.

The costs involved and that are required to be incurred by hospitals for BMW management can be classified as capital and recurring costs. Capital costs are one-time expenses or fixed costs. It includes procurement of plastic bins for discarding or disposing waste, transport trolleys used for transporting waste from source of generation to internal storage area, sharp containers for sharp disposal, personal protective equipment like rubber shoes worn by waste handlers during packaging and transportation. Recurring cost is a regular occurring cost over a period of time. This includes cost of consumables like color-coded bags, personal protective equipment like plastic apron, face masks, gloves, cost of training employees, salary for waste handlers, and cost of outsourcing.

Analyzing these costs and comparing the costs incurred under several cost heads will help an administrator prioritize spending to achieve compliance to BMW management.

\section{AIMS}

To assess costs associated with BMW management in three different hospitals and identify priorities to improve compliance.

\section{OBJECTIVES}

- To study and compare BMW management process at three different hospitals

- To understand the various costs involved in the BMW management process (internal and external) and determine focus area for spending to improve compliance to BMW management.

\section{MATERIALS AND METHODS}

Descriptive cross-sectional study was carried out, to study the compliance of BMW management at three different hospitals with respect to Bio-Medical Waste (Management and Handling) Rules, 2011. A retrospective study was conducted to analyze cost data for a 1-year time period. Cost involved in BMW management was analyzed and classified as capital and recurring costs. The study was undertaken in Udupi taluk; the taluk comprises 11 hospitals (1 Government and 10 private hospitals). The hospitals were selected using convenient sampling, but taking permission to conduct the study was difficult. Only three hospitals were permitted to carry out the study.

The variables for assessing BMW management as per the compliance requirements of the protocol of BMW (REF). 
The study was conducted at the following hospitals:

- A private accredited large tertiary care teaching hospital (2032 bedded): Hospital A

- A private nonaccredited nonteaching medium size hospital (268 bedded): Hospital B

- A private nonaccredited small hospital (112 bedded): Hospital C

Observation of workflow, process, and other activities related to BMW management:

- To study and compare process, workflow of handling BMW at different institutions.

- To observe support activities like training program, immunization schedules, and auditing.

Perusal of records in purchase department, finance department, and human resource department (where applicable) to obtain the information on costs.

Ascertaining costs under the following cost heads: Capital cost, recurring cost, cost per bed/day.

\section{RESULTS}

The study was conducted in three hospitals in Udupi District of Karnataka. One was a large tertiary care teaching hospital. It was accredited by National Accreditation Board for Hospital and Health care (NABH) providers. The other two hospitals were nonaccredited nonteaching hospitals. Requisite permission to conduct the study was obtained from the administrators of the respective hospitals. Two observers (author and independent observer) were involved in the study.

Comparison of the hospital under study with respect to bed strength, accreditation status, and observation of BMW handling process has been tabulated in Table 1.

Segregation at source and sorting into color-coded bags is followed diligently in hospital A. In hospitals B and C, waste was not sorted according to Schedule II though color-coded bags were present. It appeared to be because of lack of awareness and training.
Internal transport within the hospital premises was found to be compliant in all three hospitals. It was transported in closed trolleys with Biohazard symbol marked on it. All waste handlers were provided personal protective equipment to handle waste. Immunization of employees was $100 \%$ in hospital A. In hospital B, immunization was provided by the hospital at discounted price; however, it was not documented. In hospital C, waste handlers were not aware of immunization and record of immunization provided by hospital was not available.

Common storage area within the premises where waste is collected before final disposal was present in all the three hospitals. However, the storage area in hospital $C$ did not have doors and was close to underground water tank.

All the three hospitals have outsourced final disposal of waste to common BMW treatment facility. All wastes are weighed before transportation.

Regular training programs were conducted for housekeeping workers and nursing staff in hospital A. It consisted of lecture classes and onsite demonstration. Every new employee was provided training during the orientation program. Retraining for staff was provided once in 2 years. The hospitals $B$ and $C$ had informal training session. Nursing superintendent/Ward in-charge brief staff regarding segregation of waste. During our observation, we found that the sorting of waste into designated color-coded bags was not done as per Schedule II of BMW Rules. Compliance to BMW management is directly related to the knowledge and awareness about process and this attitude and knowledge is updated with the help of periodic training in the subject. It is evident from various studies that training should be an essential part of the hospital employee's daily activity so as to have proper and scientific management of the BMW generated in the hospital. ${ }^{4,10}$

Table 1: Comparison of hospital characteristics

\begin{tabular}{llll}
\hline & Hospital A & Hospital B & Hospital C \\
\hline Type & Accredited teaching & Nonaccredited nonteaching & $\begin{array}{l}\text { Nonaccredited nonteaching } \\
\text { hospital }\end{array}$ \\
& hospital & hospital & 112 \\
Bed strength & 2,030 & 268 & Partial compliance \\
Segregation at source & Compliant & Partial compliance & Present \\
Color-coded bins/plastic bags & Present & Present & Present \\
Sharp containers & Present & Present & Compliant \\
Internal transport & Compliant & Compliant & Present and noncompliant \\
Common storage area & Present and compliant & Present and compliant & Nil \\
Treatment within premises & Nil & Nil & Outsourced \\
Final disposal & Outsourced & Outsourced & No \\
Training of waste handlers & Yes & No record maintained & No record maintained \\
Immunization (Hep B) & Yes & Present in OT, ICU, OPD & Nil \\
Signage/IEC material & Present in all areas & & \\
\hline
\end{tabular}




\section{Cost of Handling BMW}

Cost data was obtained after perusal of records maintained in hospital. Informal discussion with administrators and departmental in-charges was done for apportionment of cost. Since housekeeping staff perform functions apart from waste handling, it was found appropriate to apportion the cost. Cost for managing BMW was classified as capital cost and recurring cost. These costs are presented in Tables 2 and 3.

Total cost of managing BMW was calculated by adding capital cost and recurring cost as shown in Table 4 . It was found that 70 to $80 \%$ of cost was incurred toward recurring expenses in all the three hospitals. Cost per bed/day is useful indicator to understand the cost of providing service. From Table 4, we can understand that, hospital A spent Rs 7.7 per bed/day, hospital B spent Rs 8.8 per bed/day, and hospital C spent 12.4 per bed/day. Hospital incurred higher recurring cost on procurement of consumables. Higher cost per bed/day at lower centers can be attributed to inability to bargain with vendors while procuring consumables which form a major part of recurring expenses.

Table 2: Capital cost incurred for the management of BMW in three hospitals

\begin{tabular}{llll}
\hline Capital cost & Hospital A & Hospital B & Hospital C \\
\hline Sharps containers & 846,388 & 48,534 & 11,760 \\
Waste bins & 113,823 & 9,800 & 3,760 \\
PPE (shoes) & 10,500 & 2,000 & 1,350 \\
Trolleys & 162,000 & 28,000 & 25,000 \\
Transport bins & 52,000 & 18,000 & 16,450 \\
Signboards/IEC & 116,000 & & \\
material & & & \\
\hline Total capital cost & $1,300,711$ & 106,334 & 58,320 \\
(A) in rupee & & & \\
\hline
\end{tabular}

Table 3: Recurring cost incurred for the management of BMW in three hospitals

\begin{tabular}{llll}
\hline Recurring cost & Hospital A & Hospital B & Hospital C \\
\hline Plastic bags & $2,057,973$ & 391,280 & 102,200 \\
PPE (apron, & 150,100 & 51,533 & 25,417 \\
gloves, face mask) & & & \\
Vaccination & 35,615 & 2,700 & \\
Training & 135,642 & & \\
Salary & 819,000 & 106,000 & 221,760 \\
Outsourcing & $1,195,232$ & 199,205 & 99,603 \\
\hline Total recurring cost & $4,393,562$ & 750,719 & 448,979 \\
(B) in rupee & & & \\
\hline
\end{tabular}

Table 4: Total cost incurred for the management of BMW and cost per bed/day

\begin{tabular}{llll}
\hline $\begin{array}{l}\text { Total cost }=\text { cost }(A)+\operatorname{cost}(B) \\
\text { in rupee }\end{array}$ & $5,694,273$ & 857,053 & 507,299 \\
Cost/bed/day in rupee & 7.7 & 8.8 & 12.4 \\
\hline
\end{tabular}

\section{DISCUSSION}

Partial compliance in segregation of BMW was seen in hospitals B and C. In a study conducted by Sengodan, ${ }^{11}$ it was shown that effective segregation significantly reduced BMW generation and reduction was achieved despite increase in inpatient numbers.

Training of wastehandlers wasnot present in hospitals B and $C$ but regular periodic training was provided to all the waste handlers in the hospital. In a study conducted by Mathur et al, ${ }^{8}$ lack of proper and complete knowledge about BMW management impacts practices of appropriate waste disposal; therefore, it is essential to emphasize on training regarding proper management of BMW waste. It was also observed that ignorance of proper practices was more among sanitary level of waste handlers. Another study, conducted by Indian Council of Medical Research and INCLEN program evaluation network, ${ }^{7}$ conducted across 25 districts of across 20 Indian states found during in-depth interviews, the gap in knowledge and practice in relation to availability of resources and processes in place was found and the need for organized training and structured supervision to bridge this gap. A study on tertiary care hospitals in India found that people with higher education, such as consultants, residents, and scientists had good knowledge of biomedical rules but was not reflected in their practices. ${ }^{12,13}$

United Nation Industrial Development Organization (UNIDO) reported that geographically diverse, large states of India (Andhra Pradesh, Maharashtra, and Uttar Pradesh) had shown that awareness among hospital staffs regarding segregation of BMW was slightly higher in urban areas compared to rural areas; and that employee training and awareness can be a major determinant of establishing optimal BMW. ${ }^{14}$

Presence of a common storage area was seen in all the three hospitals; however, compliance was deficient in hospital $\mathrm{B}$. The $\mathrm{WHO}^{15}$ suggests that waste, in bags or containers, should be stored in a separate area, room, or building of a size appropriate to the quantities of waste produced and the frequency of collection. The storage should not exceed the time limit in the following cases of climate:

- Temperate climate: 72 hours in winter and 48 hours in summer

- Warm climate: 48 hours during the cool season

- 24 hours during the hot season

Cost per bed for BMW disposal with outsourced agency was much lesser for hospital A when compared to the other respective hospitals as none of the hospitals had an in-house facility to treat. In a study, conducted by Jindal et $\mathrm{a}^{16}$ on system analysis of BMW, it was suggested to explore outsourcing BMW for disposal as a viable option and cost effective, and also it was found 
that waste generated in color-code yellow ranged from 64.25 to $27.345 \mathrm{gm} /$ day/bed; in color-code red from 19.37 to $10.97 \mathrm{gm} /$ day/bed; and in color-code blue from 3.295 to $3.82 \mathrm{gm} /$ day/bed. Range of price quoted (Rs/day/ bed) by various Health Care Establishments (HCEs) for outsourcing was between Rs 1.89 and Rs 8.60 with an average of approximately Rs 5.00 per day per bed. Cost variation was seen as per the location of the HCE.

\section{CONCLUSION}

- Training was essential to ensure compliance to BMW (Handling and Management) rules. It is difficult for small health care organizations to conduct regular training of staff. Attrition among staff also discourages administrators to avoid training. Training session can be organized by Government at taluka level or district level to encourage small health care organization to enroll their staff.

- Common BMW treatment facility can supply colorcoded bags at uniform prices to all health care facilities irrespective of their bed strength. This will reduce burden on small health care organizations.

\section{LIMITATION}

There are limited studies related to costing of BMW management. Similar studies were conducted 20 years back but could not be used for comparison because of the factors like inflation, intercity variations in prices of consumables, outsourcing costs and all.

\section{REFERENCES}

1. Mathur P, Patan S, Shobhawat AS. Need of biomedical waste management system in hospitals - an emerging issue - a review. Curr World Environ 2012;7(1):117-124.

2. Ministry of Environment and Forest, Govt. of India. BioMedical Waste (Management \&amp; Handling) Rules, 2011. http://www.moef.nic.in/downloads/public-information/ salient- features-draft- bmwmh.pdf. [accessed 25.07.16]

3. Dash A, Kumar S. Thermolysis of medical waste (waste syringe) to liquid fuel using semi batch reactor. Waste Biomass Valorization [Internet]. 2015;6(4):507-514. Available from: http://dx.doi.org/10.1007/s12649-015-9382-3.
4. Lakshmi BS, Kumar P. Awareness about bio-medical waste management among health care personnel of some important medical centers in Agra. Int J Eng Res Tech 2012;1(7):1-5.

5. Lee BK, Ellenbecker MJ, Moure-Ersaso R. Alternatives for treatment and disposal cost reduction of regulated medical wastes. Waste Manag 2004;24(2):143-151.

6. World Health Organization. Health-care waste [Internet]. Geneva: World Health Organization 2016 [cited 2016 May 11]. Available from: http://www.who.int/mediacentre/ factsheets/fs253/en/.

7. INCLEN Program Evaluation Network (IPEN) Study Group. Bio-medical waste management: situational analysis \& predictors of performances in 25 districts across 20 Indian States. Indian J Med Res 2014 Jan;139(1):141-53.

8. Mathur V, Dwivedi S, Hassan MA, Misra RP. Knowledge, attitude, and practices about biomedical waste management among health care personnel: a cross-sectional study. Indian J Community Med 2011 Apr-Jun;36(2):143-145.

9. World Health Organization (WHO). Bio-medical waste management self learning document for nurses \& paramedical. Hyderabad, Andhra Pradesh, India: Environment Protection Training and Research Institute; 2004.

10. Basarkar S. Appraisal of effect of training on biomedical waste management in health care facility: an analytical study. Int J Sci Res Publication 2014 Mar;4(3):1-6.

11. Sengodan VC. Segregation of biomedical waste in a South Indian tertiary care hospital. J Nat Sci Biol Med 2014 Jul-Dec; 5(2): 378-382.

12. Saini S, Nagarajan SS, Sarma RK. Knowledge, attitude and practices of bio-medical waste management amongst staff of a tertiary level hospital in India. J Acad Hosp Administr 2005; 17:1-12.

13. United Nations Industrial Development Organization (UNIDO). UNIIDO Launches of 40 million dollar project to help India dispose of bio-medical waste; 2010 Feb 11 (accessed 2013 May 12). Available from: http://www.unido.org/news/ press/unido-waste-2.html.

14. World Health Organization. Handling, storage, and transportation of health-care waste [Internet]. Geneva: World Health Organization.http://www.who.int/water_sanitation_health/ medicalwaste/061to076.pdf [accessed 25.07.16]

15. World Health Organization. Cost related to health-care waste management [Internet]. Geneva: World Health Organization; 1994 [cited 2016 May 11]. Available from: http://www.who. int/water_sanitation_health/medicalwaste/135to139.pdf.

16. Jindal A, Gupta A, Grewal V, Mahen A. Biomedical waste disposal: a systems analysis. Med J Armed Forces India 2013 Oct;69(4):351-356. 